\title{
PROJETOS DIDÁTICOS COMO SUPORTES ESTRATÉGICOS AO ENSINO DE MATEMÁTICA NA EDUCAÇÃO DE JOVENS E ADULTOS
}

\section{ARTIGO ORIGINAL}

SILVA, Roberto Carlos da ${ }^{1}$

SILVA, Roberto Carlos da. Projetos didáticos como suportes estratégicos ao ensino de matemática na educação de jovens e adultos. Revista Científica Multidisciplinar Núcleo do Conhecimento. Ano 05, Ed. 09, Vol. 06, pp. 131-141. Setembro de 2020. ISSN: 2448-0959, Link de acesso: https://www.nucleodoconhecimento.com.br/educacao/suportes-estrategicos

\section{RESUMO}

Neste trabalho discute-se que a forma pela qual as aulas de matemática na educação de jovens e adultos têm sido conduzidas pode ser um dos fatores do fracasso escolar, e consequente abandono dos alunos. Analisa-se o modelo tradicional de aulas expositivas no ensino de matemática. Em seguida, é sugerido a metodologia de trabalho com projeto didático, com intuito de que se possa romper com a situação de estagnação e perplexidade dos alunos neste segmento do ensino. Realizou-se uma pesquisa bibliográfica considerando as contribuições de Rego e Rego (2000), Pellanda (2009), Moran (2006), Bassanezi (2002), Moura, Santos (2011), Amstrong, Vargas (2012), entre outros. Utilizando metodologias alternativas ao ensino tradicional há possibilidade de dinamizar a rotina escolar levando o discente a interessar-se mais pelas aulas, ter maior participação e consequentemente aprender de forma significativa e permanente.

1 Mestre em Educação (2004) pela Universidade Federal de Sergipe - UFS; Especialista em Novas Tecnologias e Desenvolvimento Regional ((2000) pela UFS; Licenciado em Pedagogia (1990) pela UFS; e Licenciado em Matemática (2014) pela Faculdade de Ciências da Bahia - FACIBA. 
Palavras-Chave: Matemática, Educação de Jovens e Adultos, Projetos de Ensino.

\section{INTRODUÇÃO}

O presente trabalho tem como tema "Projetos didáticos como suportes estratégicos ao ensino de matemática na educação de jovens e adultos", considerando-se que a matemática é um dos componentes curriculares estudados pelos alunos desta modalidade de ensino que assume grande relevância no desenvolvimento de conhecimentos e habilidades necessárias à vida cidadã e as relações que estes jovens e adultos estabelecem no âmbito da sociedade.

Realizar cálculos, manipular números, medir, comparar, interpretar, formular e resolver problemas, equacionar, simular, ter simetria e regularidade nos desenhos geométricos e resolver questões que envolvem as operações aritméticas, são importantes aquisições para o cotidiano dos educandos da Educação de Jovens e Adultos.

Nesta perspectiva construiu-se questões que norteiam este trabalho:

- Apesar de ser um componente curricular com conteúdos relevantes, por que poucos alunos conseguem aprender matemática? Seria em função da complexidade dos conteúdos que são apresentados de forma abstrata e superficial?

- Por que muitos alunos têm certa apatia e medo de estudar e aprender matemática?

Estas questões suscitaram o interesse da pesquisa devido a minha condição de docente protagonista do ensino de matemática na educação de jovens e adultos, e nesta condição, tenho percebido alunos desmotivados e desinteressados, sendo esta reclamação disseminada por diversos colegas da área.

Na perspectiva de modificar esta realidade, é imprescindível que o educador busque metodologias alternativas a este método de ensino, visando melhorar o interesse e desempenho dos alunos, mudando a visão que se tem de matemática como "a 
disciplina difícil, complicada", o "Bicho papão" e levando-os a perceberem como um verdadeiro instrumento de vida cidadã, onde seus estudos Ihes trarão conhecimentos e habilidades necessários ás praticas cotidianas efetivas e conscientes.

Para tanto, deve-se mudar a perspectiva de ensino buscando alternativas pedagógicas que resiguinifiquem a matemática na vida das pessoas. Sugere-se a inserção de projetos didáticos nas aulas de matemática das turmas de Educação de Jovens e Adultos, visando melhorar a aprendizagem e melhorar a autoestima dos alunos.

Neste sentido, discute-se que a maneira pela qual as aulas de matemática na educação de jovens e adultos estão sendo ministradas pode ser um dos fatores que levam a desmotivação e o desinteresse dos alunos na educação de jovens e adultos. Para tentar auxiliar no entendimento dessa situação, propõe-se analisar o modo como a maioria das escolas propõem suas práticas pedagógicas no ensino de matemática, como também, indicar alternativas a esta situação.

Primeiramente, discute-se o modelo tradicional de aulas expositivas no ensino de matemática. Em seguida, é sugerido a metodologia alternativa: o trabalho com projeto didático, com intuito de que se possa romper com a situação de estagnação e perplexidade dos alunos neste segmento do ensino. Daí a relevância deste trabalho.

\section{O CONTEXTO DO ENSINO DE MATEMÁTICA NA EDUCAÇÃO DE JOVENS E ADULTOS}

O ensino de matemática nas classes de educação de jovens e adultos tem se tornado um grande desafio para grande parte dos professores devido a realidade que se apresenta: alunos desmotivados e desinteressados e grande antipatia ao componente curricular (não gostam de matemática, não aprendem matemática). Não bastasse isso, o conhecimento nesta área requer uma aprendizagem que vai além da leitura e debate do texto do livro didático ou responder uma lista de exercícios ou decorar uma fórmula, mas a inserção do educando em outros textos e contextos, que para muitos educadores gera certas dificuldades. 
Além disso, os professores de escola pública, mais especificamente os que lecionam matemática na educação de jovens e adultos, se deparam com um contexto diverso no que diz respeito aos próprios alunos, famílias e culturas, ritmos de aprendizagem, desigualdades econômicas, sociais e culturais, tipos de resistências e preconceitos, além da falta de apoio familiar e de recursos didáticos e tecnológicos.

No que diz respeito a aprendizagem de conteúdos de matemática pelos alunos da educação de jovens e adultos, se dar de forma lenta e não permanente, diante da maneira como os conteúdos são abordados (de forma abstrata, distantes de suas realidades) e se tornam de difícil compreensão por parte destes educandos. Neste sentido, explicita Fisher (2014, p. 08):

No Ensino Fundamental há uma mobilidade maior que, por vezes, cai em mal-entendidos e confusões. Não raro ser interpretado como uma listagem de termos a serem memorizados. Já no Ensino Médio o tradicionalismo é muito mais evidente, pois são disciplinas que trazem uma abstração de conceitos distanciados da realidade dos alunos. É relevante, também, a ênfase nos exercícios, na repetição de conceitos ou fórmulas, pois através da memorização se visa disciplinar a mente e formar hábito, o que acaba por adestrar os alunos.

Neste sentido, precisa-se criar estratégias para que o conhecimento científico construído deixe de ser "algo inalcançável", desestimulante, vazio, e se torne significativo, sendo conectado com o universo da cada um, estimulando a curiosidade, a investigação, o envolvimento, o gosto pela pesquisa, pelo cálculo, a comparação, a descoberta.

Assim, se faz necessário repensar as aulas da educação de Jovens e Adultos, especialmente as de matemática, visando imbuir mais significado para os alunos. Desta forma, o presente trabalho, primeiramente, discute-se o ensino de matemática neste segmento de ensino na perspectiva do modelo tradicional, em virtude de ser uma prática bastante usual na escola nos dias atuais. A partir destes esclarecimentos, apresenta-se alternativas de trabalho pedagógico para o componente curricular Matemática, mais especificamente, o trabalho através de projetos didáticos, este visando estimular uma participação ativa dos alunos e consequentemente uma aprendizagem mais relevante. 
A metodologia da escola tradicional, também denominada de conteudista ou convencional, tem predominância desde o século XIX, e, apesar de não ser considerada a mais adequada, pela a maioria dos protagonistas da educação, para desenvolvimento de práticas escolares contemporâneas, é bastante exercitada na realidade. Este método de ensino foca o contato com os conhecimentos existentes sobre determinado tema utilizando como estratégia pedagógica as aulas expositivas, tendo o professor e o livro didático as únicas fontes de informação, o incentivo à memorização de definições.

Para Armstrong e Vargas (2012, p. 05), na escola tradicional

O professor transmite seus conhecimentos, os métodos usuais de ensino são aulas expositivas, utiliza-se de técnicas de perguntas e respostas, o aluno é sujeito passivo do processo de ensino-aprendizagem, cabe a este apenas ouvir a explicação e copiar, este deve trabalhar a memorização de conceitos, repetição da informação recebida.

Apresentando-se desta maneira, o ensino de matemática, não tem trazido resultados satisfatórios, sobretudo a aquisição de conhecimentos por parte dos educandos. Uma das possíveis causas apontadas para esse déficit é a maneira de ensinar os conteúdos da disciplina, que muitas vezes é baseada em concepções metodológicas que não despertam os interesses dos alunos. Em muitas salas de aula, a matemática é algo pouco atraente para os alunos, gerando, a partir das suas práticas, uma relação de medo, falta de vontade, baixa autoestima e falta de êxito.

Corroborando com esta análise, Moysés (2007, p.67), destaca:

Se professores e alunos se defrontam com sentenças, regras e símbolos matemáticos sem que nenhum deles consiga dar sentido e significado a tal simbologia, então a escola continua a negar ao aluno (...) uma das formas essenciais de ler, interpretar e explicar o mundo.

Assim, a aprendizagem de matemática tem se apresentado fragilizada, sem muito significado para o aluno, faltando-Ihes oportunizar a construção de conceitos e habilidades que serão necessários ao entendimento do mundo físico, natural e social. 
Segundo Moran (2006), existe uma importante fragilidade no aprendizado, pois faltam estímulos e metodologias adequados para tornar o aprendizado mais significativos aos educandos precisamos repensar o ensino e incentivar propostas mais dinâmicas em sala de aula.

No atual ensino de matemática na maioria das escolas públicas brasileira esta abordagem de Moran se encaixa perfeitamente, pois o mesmo tem sido muito superficial e o professor, na maioria das vezes, transcreve na lousa listas de exercícios para os alunos estudarem para as provas escritas, cabendo a elas decorar, regras, fórmulas, conceitos.

Entretanto, o ensino da matemática deve objetivar uma prática pedagógica que busque dialogar com a realidade do aluno envolvendo as relações entre ensinoaprendizagem e conhecimento matemático através da investigação e produção de conhecimento.

Neste sentido, Rêgo e Rêgo (2000, p.14) enfatiza que

é imprescindível a introdução de novas metodologias de ensino, onde o aluno seja sujeito da aprendizagem, respeitando-se o seu contexto e levando em consideração os aspectos recreativos e lúdicos das motivações próprias de sua idade, sua imensa curiosidade e desejo de realizar atividades em grupo.

Diante da realidade, onde a maioria dos alunos se encontram desmotivados e apreensivos com a matemática que vem sendo trabalhada na concepção pedagógica tradicional, será imprescindível experimentar novas metodologias e tecnologias de ensino visando aproximar os alunos dos conteúdos abordados em sala de aula, tornando-os sujeitos ativos no processo de ensino-aprendizagem, propiciando desafios e descobertas, favorecendo o gosto para lidar com o conhecimento matemático e sua consequente aplicação no cotidiano.

Nesta perspectiva, aborda-se a seguir a metodologia de projetos como uma das possibilidades de ressignificar o ensino e a aprendizagem de matemática. 


\section{MUDANDO DE PERSPECTIVA: O TRABALHO COM PROJETOS DIDÁTICOS}

O conhecimento disciplinar, organizado na escola atual, está sendo constantemente foco de discussões e críticas por parte de estudiosos da educação, tendo em vista a fragmentação do conhecimento e sobretudo a inexistência de elos entre os diversos componentes curriculares disseminados na sala de aula.

Para Pellanda (2009, p. 18),

a realidade, ainda hoje, é percebida por muitos professores de forma linear, fragmentada, como uma coleção de coisas, e estável. Esta maneira de perceber representa o paradigma da simplificação, porque se refere a um modo mutilador de organização do conhecimento, incapaz de reconhecer e aprender a complexidade do real.

Neste contexto, há de se repensar a forma como o processo de ensino e aprendizagem está sendo processado na escola, pois o conhecimento dentro do processo educativo, segundo Pellanda (2009), "não existe sem experiência pessoal, onde o sujeito emerge juntamente com o conhecer". Dessa forma, o sujeito produzirá o conhecimento que é o instrumental que irá o conectar com a realidade.

A partir desta perspectiva é salutar que o professor reflita e discuta junto ao coletivo da escola, mais especificamente, seus colegas de regência, quais metodologias e conhecimentos devem ser dimensionados para que os educandos construam conhecimentos que sejam significativos para seu cotidiano e realidade.

No que diz respeito ao ensino de Matemática, a situação ainda é mais peculiar, pois são trabalhados conceitos científicos de difícil compreensão e visualização por parte dos alunos haja vista não terem sido informados da mesma maneira como foram produzidos e com grande teor de abstração. Assim compete aos professores buscar modelos e metodologias adequadas para que tais conteúdos escolares se tornem acessíveis e compreensíveis no universo dos alunos (CHEVALLARD,1998), e, dessa forma, uma aprendizagem significativa. 
Para Moreira (2006), a aprendizagem significativa envolve três conceitos: significado, interação e conhecimento. Entretanto, para que estes três conceitos sejam trabalhados de forma intensa e significativa proporcionando ao aluno este tipo de aprendizagem, há de recorrer a uma mudança metodológica na sala de aula, que dentre os caminhos possíveis está o trabalho com projetos didáticos.

Segundo Moura (2011), o trabalho escolar com a metodologia de projetos promove o envolvimento ativo do aluno, potencializa as habilidades de trabalho em grupo, a cooperação e incentiva a curiosidade, possibilitando assim a descoberta e a construção do conhecimento pelo próprio aluno.

E ainda, para Moura (2011), na sociedade contemporânea, impulsionada por constantes mudanças e inovações, o trabalho com projetos poderá propiciar mais segurança e eficiência na busca do conhecimento, pois muitos resultados decorrentes de projetos educacionais ocorre apenas com ajustes nas atividades de rotina do sistema

O desenvolvimento de aulas de matemática através de projetos didáticos promoverá a aquisição de conhecimentos e habilidades como as tarefas em equipes, a pesquisa de campo, a organização e interpretação dos dados, a realização de cálculos e apresentação dos resultados de situações-problemas provenientes do contexto do próprio aluno, que são raramente exercitadas na metodologia tradicional.

Segundo Moura (2011, p. 16),

ao participar de um projeto ocorre um enriquecimento da bagagem cognitiva, da possibilidade de novas experiências e aquisição de habilidades, podendo ser solução para vários problemas registrados dentro do cotidiano escolar e da sala de aula.

O projeto de ensino é construído com os discentes a partir de acordos feitos com o professor sobre determinado problema que está colocado na realidade, daí surgindo necessidades de trabalhar conteúdos matemáticos e consequentemente, efetuar cálculos, medidas, ajustes de contas, aproximações, orçamentos, estimativas, cálculos algébricos, entre outros. 
Assim, dentro do novo contexto social, a escola precisa pensar formas de agir, de forma que mobilize o educando para a aquisição de conhecimentos e habilidades que Ihes propicie uma atuação mais consciente no seu meio social, de forma ativa, participativa e atuante, transformando-se e promovendo as transformações. Agindo assim, educadores e educandos, não focalizam somente o fenômeno educacional, mas também as questões da realidade que envolvem o seu cotidiano e a complexidade dos sujeitos que fazem parte dela.

Delimitada a importância de se trabalhar na escola com a metodologia de projeto, a seguir procede-se algumas reflexões sobre a sua estruturação.

Conforme Santos (2011), é necessário levar em conta vários fatores para a elaboração de um projeto de trabalho, como a seleção do tema; gerenciamento de trabalhos docentes e de alunos; pesquisas de fontes de informação e desenvolvimento de relatórios de projetos.

Para a escolha do tema de um projeto deve se levar em conta as questões estimuladas pelos alunos em decorrência de sua vivência e seus interesses, ou por questões levantadas através de situações apresentadas pelo professor. No entanto, se não houver iniciativa sobre determinado tema de pesquisa por parte dos alunos, cabe ao professor propor o tema e estabelecer formas de envolvimento dos alunos (SANTOS, 2011).

Existem outras formas para incentivar a iniciativa dos alunos na construção de um projeto: uma reportagem, uma fotografia, um documentário ou um vídeo; visitar uma área de plantações ou de criação de animais ou entrevistar um profissional da área, como também as questões ambientais, políticas, econômicas e sociais. No campo da matemática a criação de situações que propiciem motivar o aluno será, muitas vezes, o ponto de partida para projetos ou para investigação de um fenômeno, objetos de natureza socioeconômica.

Quanto a organização do trabalho do professor em relação a um projeto não há uma regra geral, pois tudo dependerá do tema e da possibilidade de envolvimento dos 
alunos. Cabe ao professor prever os objetivos e conteúdos iniciais do projeto, levantar o material necessário para o desenvolvimento e as formas de fazer o seu encerramento.

Já com relação as características da organização do trabalho do aluno e a busca de fontes de informação dependem da abrangência do projeto. Como pode envolver atividades fora da sala de aula, o professor deverá ter um cuidado especial com tais momentos e provavelmente precisará contar com a colaboração da equipe da escola e de pais de alunos. No que diz respeito a busca de informações pode se utilizar de diversas fontes, inclusive as midiáticas, para que o aluno aprofunde os conhecimentos a respeito do tema que vai trabalhar. Na sequência deve se trabalhar com os alunos a construção do relatório de pesquisa, sempre observando as normas cientificas de construção.

Neste contexto, o professor da Educação de Jovens e Adultos, em específico o professor de Matemática, busca auxiliar os alunos nas dificuldades apresentadas na disciplina, principalmente para aqueles que estiveram afastados muitos anos da sala de aula, resgatando seus saberes e estabelecendo uma relação dialética-teoriaprática entre o saber que eles possuem e o conhecimento matemático que é aplicado, através de metodologias que estruturam o campo científico da própria matemática, assim, o projeto de ensino é uma construção peculiar, enquanto modelagem matemática.

Corroborando com esta perspectiva, Bassanezi (2002, p. 11), destaca que "uma metodologia educacional eficaz para o ensino da Matemática é a utilização da Modelagem Matemática, pois ela possibilita transformar problemas da realidade e resolvê-los interpretando suas soluções na linguagem do mundo real".

Desta forma, o professor deverá desenvolver atividades que possibilitem um ambiente investigativo que busquem em diversos aspectos a situações corriqueiras dos alunos, como destaca Barbosa (2001) que a modelagem é um meio de aprendizagem onde os alunos são instigados a problematização e a pesquisa em situações reais, por meio da matemática. 
Neste contexto, o processo metodológico de ensino através de projetos é fundamental, visto que leva os alunos a uma forma diferenciada de aprendizado, em que seu saber cotidiano se articula com os símbolos e a linguagem matemática, se tornando essencial para a assimilação dos conteúdos matemáticos.

Neste sentido, vale salientar que os professores que se propõem a trabalhar com essa metodologia de ensino, deve estar profundamente apto a aprender. Sendo assim, a proposta do ato de ensinar, está interrelacionada com a reflexão constante sobre o que se ensina, como se ensina e quais os objetivos que se quer atingir.

\section{CONSIDERAÇÕES FINAIS}

Diante do exposto, conclui-se que o ensino de matemática não vem apresentando resultados satisfatórios para professores e alunos, principalmente, se conduzido diante de uma perspectiva conteudista, tradicional. Os alunos não conseguem aprender de forma significativa para aplicar estes conhecimentos adquiridos na escola para a sua vida prática. Há necessidade de repensar as aulas de matemática, especialmente na educação de jovens e adultos, trazendo-Ihes mais significado e participação ativa dos alunos na tarefa de construção do conhecimento.

O projeto didático é uma metodologia alternativa ao modelo tradicional de ensino visto que ao invés de trabalhar cálculos abstratos, memorização de regras sem significado para o aluno, utiliza-se a busca do conhecimento pelo aluno, incentiva a pesquisa, o trabalho em grupo, a construção do conhecimento, a aquisição de habilidades como negociar, calcular usando instrumentos tecnológicos, conhecer e discutir problemas, inclusive apontando soluções.

Para o aluno da educação de Jovens e Adultos, a metodologia de projetos é bastante significativa devido a oportunidade de modelagem de sua realidade tornando-se mais interessante, próxima de si e de seus problemas. Os Projetos de ensino poderão propiciam o desenvolvimento de novas habilidades, bem como auxiliar no processo de aprendizagem de conceitos matemáticos, refletindo sua realidade, mediadas pela resolução de problemas. 
Portanto, apresenta-se os Projetos didáticos, enquanto metodologia de ensino para trabalhar matemática na educação de Jovens e Adultos, no intuito de modificar o cenário atual, já que a Matemática ainda é motivo de aversão por parte dos estudantes.

\section{REFERÊNCIAS}

ARMSTRONG, Diana Lucia de Paula; VARGAS, Liane Maria. Metodologia do ensino de ciências biológicas e da Natureza. Curitiba: Intersaberes, 2012.

BARBOSA, Jonei Cerqueira. Modelagem Matemática: Concepções e Experiências de Futuros Professores. 2001. 253 f. Tese Doutorado - Universidade Estadual Paulista "Júlio de Mesquita Filho", Rio Claro.

BASSANEZI, Rodney Carlos. Ensino-aprendizagem com Modelagem Matemática. 3. ed. São Paulo: Contexto, 2019.

CHEVALLARD, Ives. La Transposición didactica: Del saber sábio al saber enseñado. Buenos Aires: Aique Grupo Editor S. A., 1998.

FISHER, Len. A Ciência no Cotidiano: como aproveitar a ciência nas atividades do dia-a-dia. Tradução, Helena Londres. Rio de Janeiro: Jorge Zahar. 2014.

MORAN, José Manuel. Mediação pedagógica e o uso da tecnologia. In: Novas tecnologias e mediação pedagógica. MORAN, José Manuel, MASETTO, Marcos, BEHRENS, Marilda. 12ª ed. São Paulo: Papirus, 2006.

MOREIRA, Alberto da Silva. Cultura midiática e educação infantil. Educação e Sociedade, Campinas, vol. 24, n. 85, p. 1203-1235, 2006.

MOURA, Dacio G \& BARBOSA, Eduardo F. Trabalhando com projetos: Planejamento e Gestão de Projetos Educacionais. Editora Vozes, São Paulo: 2011.

MOYSÉS, Lúcia. Aplicações de Vygotsky à Educação Matemática. Campinas: Papirus, 2007. 
PELLANDA, Nize Maria Campos. Maturana \& a Educação. Belo Horizonte: Autêntica Editora, 2009.

RÊGO, R.G.; RÊGO, R.M. Matemática ativa. João Pessoa: Universitária/UFPB, INEP, Comped: 2000.

SANTOS, Widson Luis Pereira dos. Contextualização no ensino de ciências por meio de temas CTS em uma perspectiva Crítica. Ciência \& Ensino, v. 1, número especial, nov. 2011.

Enviado: Maio, 2020.

Aprovado: Setembro, 2020. 